\title{
Editorial
}

\section{Identification of the presence and impact of Japanese knotweed on development sites}

\author{
Journal of Building Appraisal (2010) 5, 289-292. doi:10.1057/jba.2010.2
}

During the last decade the work of the building appraiser/surveyor has become more complicated. Legislation like the Disability Discrimination Acts 1995 and 2005, The Control of Asbestos at Work Act 2002 and Control of Asbestos Regulations 2006, Construction Design and Management Regulations 2007, Building Regulation changes to energy consumption and retention through Approved Document L, to name just a few, have changed the focus of many building appraisals and the working practices of the appraisers. There is however a further issue that the competent appraiser must ensure is comprehensively addressed. This is the presence on or close to site of a once prized ornamental plant, Japanese Knotweed. When first made aware of problems associated with Japanese Knotweed, not that many years ago, the editor accessed a current map of knotweed presence which showed its gradual spread from Southern England. Today examples of Knotweed are readily found in the editor's professional work place of Sheffield, far to the north of that early concentration, and reputedly found all across Britain.

Japanese Knotweed, (Fallopia Japonica) is a large herbaceous plant. It was introduced as an ornamental plant in the nineteenth century, since then it has spread to become one of The World Conservation Union's world's top 100 invasive plants (Wikipedia, 2009). It has a look similar to Bamboo, with foliage consisting of leafs $70-140 \mathrm{~mm}$ long by $50-120 \mathrm{~mm}$ wide (see Figure 1). It has a profusion of tiny white flowers growing upon racemes, and can grow up to heights of $4 \mathrm{~m}$ (see Figure 2). The plant above ground is however not the main problem, although by sheer size it tends to dominate its environment to the determent of other native plant life. It also by virtue of its size and shape can capture wind-bourn waste materials thus attracting rodent pests. However, having been removed from its natural habitat in Japan its seeds are rarely viable in the UK climate. This is compensated for by its roots which can grow down up to $3 \mathrm{~m}$ and radiate outwards up to $7 \mathrm{~m}$ as it spreads by root growth. A tiny Rhizome from its roots left in situ can regenerate the plant. These Rhizomes sprout new growth as the plant advances relentlessly. The plant thrives following severe cutting back: is resistant to temperatures down to $-35^{\circ} \mathrm{C}$, can survive poor soil conditions, high $\mathrm{pH}$ levels, high levels of salinity, drought and flooding (see Figure 3). Treatment with herbicide rarely kills the plant immediately, and digging is problematical in terms of removing every gram of Rhizome, and disposal of the resultant spoil.

The root system can grow through most materials including concrete. As it spreads it grows through paths, roads and building foundations causing structural damage and failure. Land with resident knotweed is commercially blighted and knotweed cuttings and soil containing Knotweed rhizomes are a controlled waste. Chemically treated knotweed additionally becomes a hazardous waste. Buildings and infrastructure on 


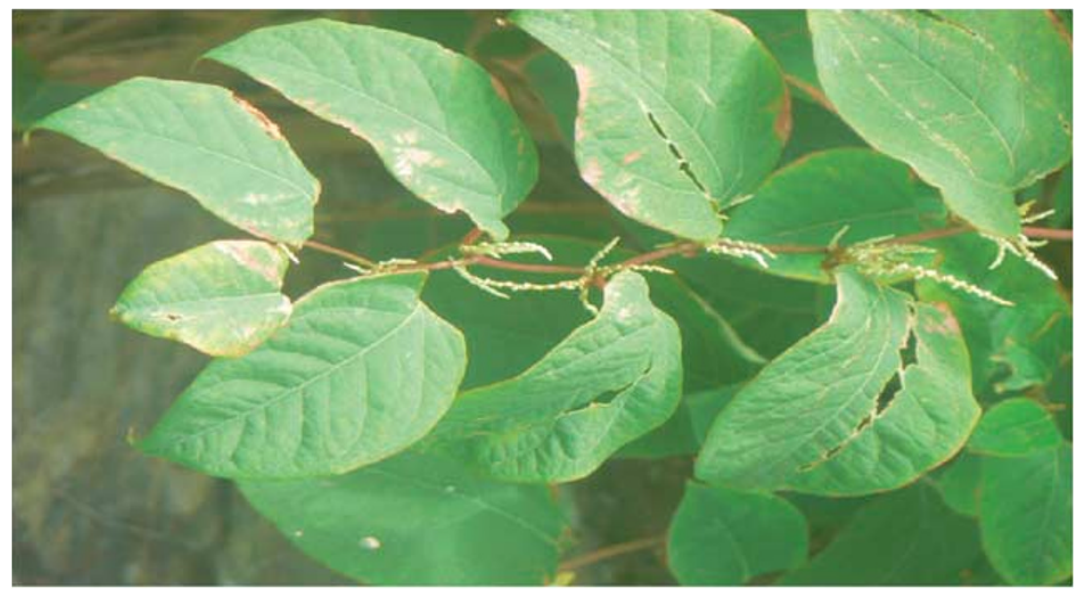

Figure I: Japanese Knotweed leaves.

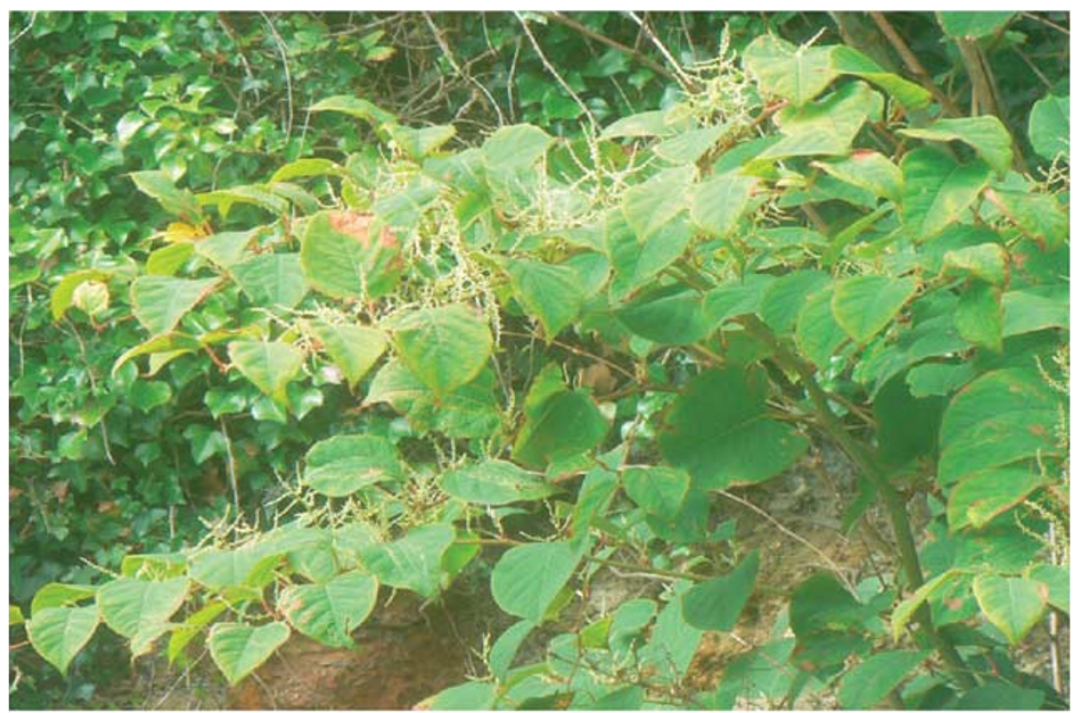

Figure 2: Knotweed leaves, stem and flowers.

a knotweed-infested site are at risk of damage, and owners of such a site have a legal duty of care to prevent its spread to neighbouring property. In summary, knotweed is physically damaging, financially debilitating and legally compromising. Purchasers looking to buy a property may therefore expect a competent surveyor to identify its presence on-site, and might reasonably be expected to seek compensation if its presence was not established during survey.

Clearly, direct treatment of Japanese Knotweed falls outside the remit of most appraisers in favour of the specialist contractor. The issues in respect of Knotweed do however need to be considered. There are two main ways to deal with Knotweed, both are problematic. Cutting the plant back and hoping it will eventually die is unlikely to be effective, and barriers often fail to contain the plant. Digging out the roots is difficult as a tiny Rhizome left in situ can regenerate. The problem with digging is that soil containing Knotweed roots is considered as contaminated by The Environmental Protection Act 1990. Removal from site other than under Environmental Agency licence 


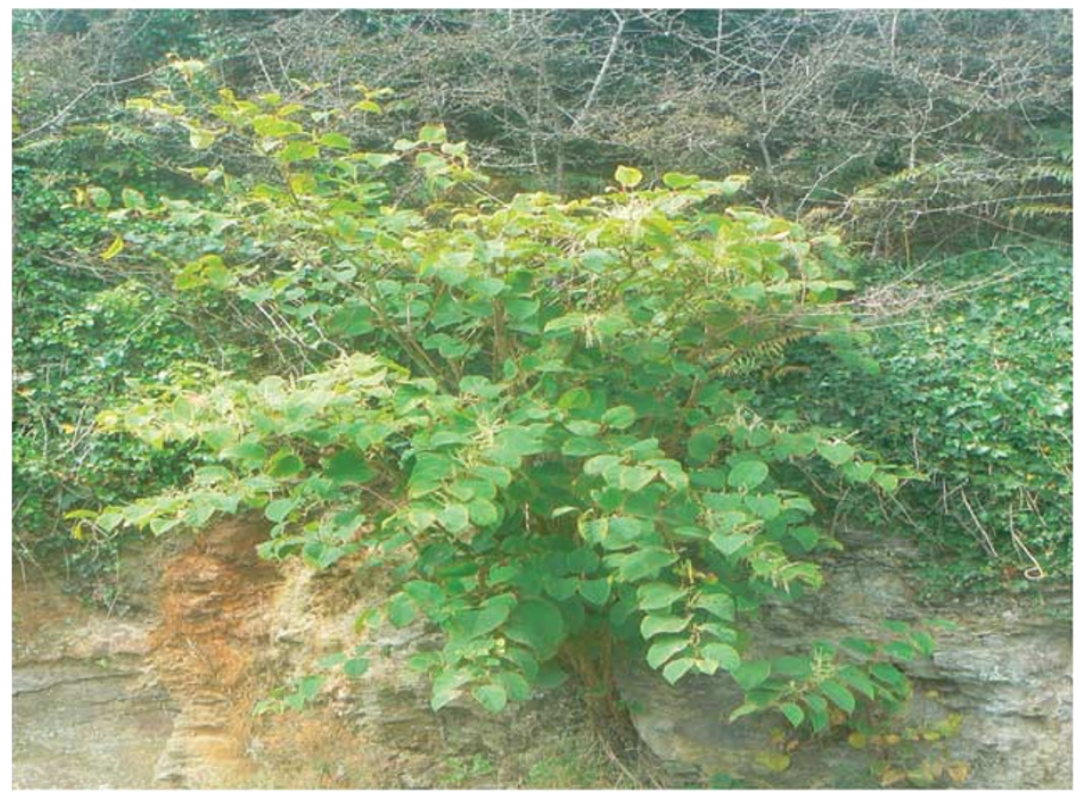

Figure 3: Knotweed growing through inhospitable terrain.

could result in a fine or even a prison sentence, and finding a landfill site which would accept it would not be easy. Japanese Knotweed is native to desert regions and as such can survive high temperatures and arid conditions. Burning the waste is therefore problematic in terms of total eradication and uncontrolled burning risks releasing sufficient live material to the atmosphere to contravene the Wildlife and Countryside Act 1981, which prohibits any actions leading to the spread of Japanese Knotweed. Encasing the soil within a concrete tomb on-site is a possible holding option as the knotweed may eventually in future years regenerate and grow through the concrete.

Chemical treatment is equally problematic. One treatment rarely succeeds and only treatment over a number of seasons with a herbicide such as Glyosophate which attacks the roots can be successful, providing the time for such a long process is available. Plant and root material treated with herbicide becomes hazardous waste under the Hazardous Waste Regulations 2005 and therefore even more controlled than before. A common way for Knotweed spread is along water courses and close to the banks of water courses is a common place to find Knotweed, which environmentally makes chemical treatment less practical, and controlled by the Environmental Protection Act 1990 (Crowhurst, 2006). Trials using more environment friendly treatments such as spraying with salt water and steam treatment have been piloted. Success rates are not documented.

Given the difficulty in eradicating Knotweed biological solutions are being considered. The introduction of Knotweed debilitating (Mycosphaerella, Leaf Spot Fungus), and a Japanese Knotweed predator insect, a Psylyd called Aphalara Itadori, which is a native insect of Japan, are the measures which are under debate. With the experience of Colorado Beetle and Australia's Horned Toad the latter measure requires great investigation before implementation.

There is a document towards which the wise surveyor should direct to any client whose site may be infested with Knotweed. This is the current Environment Agency code of practice for managing Japanese Knotweed on development sites (EA, 2008). In addition 
to strongly reinforcing the options and pitfalls of the treatment of Japanese Knotweed, it also very strongly outlines the legal position in respect of ownership of a site containing Knotweed. Three areas of advice from this guide are however ones which the prudent appraiser may wish to impart directly to a client. These are the wisdom of having legal protection built-in to any purchase agreement against discovery of Japanese Knotweed even if no visible signs of the plant are currently noted. The second is the caution which must be exercised if it is proposed to import top soil for landscaping. Finally, the advice is that if Japanese Knotweed does become a factor that overseeing its treatment is entrusted to a competent clerk of works, as the consequences of slipshod management of the process are severe.

\section{CONCLUSION}

Japanese Knotweed is a very invasive plant which can cause structural damage to infrastructure and building substructure on a contaminated site. Its presence can severely affect property prices, impact upon development proposals and create legal liabilities for the property owners. Its control is difficult, expensive and generally time consuming. Control methods invariably create adverse environmental conditions which are controlled by vigorous statute and Environment Agency action. Fortunately, managing such control is outside the remit of most professionals engaged in building and site appraisal. It does however fall to the competent professional to identify Knotweed on or around the site, and possibly to steer a client through a preliminary appraisal of the consequences of Japanese Knotweed. The consequences of such a discovery might become documented within an appraisal report. For aid it is recommended that use be made of the Environment Agency code of practice for managing Japanese Knotweed on development sites which provides details of treatment options, legal consequences and sound practical advice.

It is the advice of the editor that all building and site appraisers commit identification of Japanese Knotweed both in its growing state and winter dormant state to mind and vigorously investigate its presence during any appraisal work. Failure to do so, given its increasing profile could be professionally compromising, and given the distinctive appearance of the plant in both growing and dormant states, should be unnecessary. Meanwhile, the battle to control the spread of Knotweed particularly in its formative location of South West England goes on apace, and hopefully more effective treatments that do not carry potential environmental problems can be found, so that history does not get to view Japanese Knotweed as being Britain's equivalent of the Horned Toad.

\section{REFERENCES}

Crowhurst, G. (2006) Environmental Law and Management. Witney, OX: Lawtext Publishing.

Environment Agency (EA). (2008) Managing Japanese Knotweed on Development Sites: The Knotweed Code of Practice. Bristol: Environment Agency Publications.

Wikipedia. (2009) Japanese knotweed, www.wikipedia.org/wiki/japanese_knotweed.

Simon Mclean

Managing Editor

Sheffield Hallam University, Nottinghamshire, UK 